\title{
Exhaled air molecular profiling in relation to inflammatory subtype and activity in COPD
}

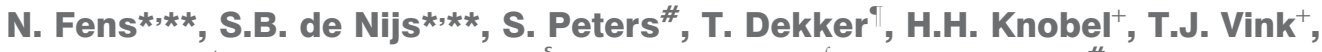 \\ N.P. Willard ${ }^{+}$, A.H. Zwinderman ${ }^{\S}$, F.H. Krouwels ${ }^{f}$, H-G. Janssen ${ }^{\#}$, \\ R. Lutter* ${ }^{\star \top}$ and P.J. Sterk*
}

ABSTRACT: Eosinophilic inflammation in chronic obstructive pulmonary disease (COPD) is predictive for responses to inhaled steroids. We hypothesised that the inflammatory subtype in mild and moderate COPD can be assessed by exhaled breath metabolomics.

Exhaled compounds were analysed using gas chromatography and mass spectrometry (GCMS) and electronic nose (eNose) in 28 COPD patients (12/16 Global Initiative for Chronic Obstructive Lung Disease (GOLD) stage $\mathrm{I} / \mathrm{II}$, respectively). Differential cell counts, eosinophil cationic protein (ECP) and myeloperoxidase (MPO) were measured in induced sputum. Relationships between exhaled compounds, eNose breathprints and sputum inflammatory markers were analysed and receiver operating characteristic (ROC) curves were constructed.

Exhaled compounds were highly associated with sputum cell counts (eight compounds with eosinophils, 17 with neutrophils; $p<0.01$ ). Only one compound (alkylated benzene) overlapped between eosinophilic and neutrophilic profiles. GC-MS and eNose breathprints were associated with markers of inflammatory activity in GOLD stage I (ECP: 19 compounds, $p<0.01$; eNose breathprint $r=0.84, p=0.002$ ) (MPO: four compounds, $p<0.01$; eNose $r=0.72, p=0.008$ ). ROC analysis for eNose showed high sensitivity and specificity for inflammatory activity in mild COPD (ECP: area under the curve (AUC) 1.00; MPO: AUC 0.96) but not for moderate COPD.

Exhaled molecular profiles are closely associated with the type of inflammatory cell and their activation status in mild and moderate COPD. This suggests that breath analysis may be used for assessment and monitoring of airway inflammation in COPD.

KEYWORDS: Airway inflammation, COPD, exhaled breath analysis, induced sputum, metabolomics, volatile organic compounds

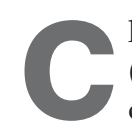

hronic obstructive pulmonary disease (COPD) is a disease characterised by incompletely reversible, progressive airflow limitation [1]. Several clinical features can be observed within the broad spectrum of COPD, including emphysema, chronic bronchitis, small airways disease and asthma-like characteristics such as airway hyperresponsiveness [2-4]. The inflammatory response in COPD is predominantly neutrophilic, but also comprises involvement of eosinophils $[5,6]$. The presence and activation status of these cells varies between subgroups of patients and may reflect distinct pathophysiological mechanisms within the disease $[7,8]$. It is increasingly acknowledged that inflammatory phenotyping of COPD patients can lead to a more effective tailored treatment. Indeed, several studies have shown a greater response to corticosteroid treatment in eosinophil-predominant COPD [9-11].
Sputum induction is a safe and reliable method of obtaining information about inflammatory cells and mediators in COPD [12]. However, it is a time consuming procedure and patients may find it unpleasant. The different clinical, immunological and oxidative mechanisms of COPD emphasise the need to provide composite profiles of biomarkers of the disease [13]. Integrative metabolomic assessment of molecular signatures by high-dimensional diagnostic techniques can provide fingerprints of disease. In COPD, this has been done at the gene expression and protein level using blood and bronchoalveolar lavage fluid [13, 14].

Exhaled air contains mixtures of gases including volatile organic compounds (VOCs) and nitric oxide (NO). Assessment of the profile of these volatiles by gas chromatography (GC) and mass spectrometry (MS), nano-sensors of an electronic
AFFILIATIONS

Depts of *Respiratory Medicine, "Experimental Immunology, and, ${ }^{\S}$ Clinical Epidemiology and Biostatistics, Academic Medical Centre, University of Amsterdam, \#Analytical-Chemistry Group, van 't Hoff Institute for Molecular Sciences, University of Amsterdam, Amsterdam,

+Philips Research, Eindhoven, and ${ }^{f}$ Dept of Pulmonology, Spaarne Hospital, Hoofddorp, The Netherlands.

**Both authors contributed equally to the study.

CORRESPONDENCE

P.J. Sterk

Academic Medical Centre, Dept of

Respiratory Medicine, F5-259

University of Amsterdam

P.0. Box 22700

NL 1100 DE Amsterdam

The Netherlands

E-mail: p.j.sterk@amc.nl

Received:

Feb 212011

Accepted after revision:

May 152011

First published online:

June 232011 
nose (eNose) and an NO analyser might lead to the discovery of novel disease-specific patterns of molecular biomarkers [15]. We have recently shown that exhaled breathprints measured by eNose can distinguish well-defined COPD from asthma [16]. It is unknown whether exhaled breathprints in COPD are related to the underlying inflammatory phenotype. If so, breathprints may reflect the type and activity of the predominant inflammatory pathways, thereby facilitating management of the disease. Since there is evidence that, for instance, oxidative stress responses are markedly different in Global Initiative for Chronic Obstructive Lung Disease (GOLD) stage I COPD compared with later stages of the disease [17-19], the underlying mechanistic profile is likely to depend on GOLD stage. Therefore, noninvasive assessment of exhaled VOCs may also provide new insights into inflammatory pathways in relation to disease stages in COPD.

In this study, we hypothesised that metabolomic exhaled breath profiling in COPD captures the cell type and activation status as reflected by differential cell counts, eosinophil cationic protein (ECP) and myeloperoxidase (MPO) in induced sputum. Furthermore, we have examined whether the association between exhaled breathprints and inflammatory markers is different between GOLD stages I and II COPD. We aimed to test this hypothesis by examining the relationship of exhaled molecular profiles measured by GC-MS, eNose and exhaled NO fraction (FeNO) analyser, with markers of inflammation from induced sputum in COPD patients with mild and moderately severe disease.

\section{METHODS}

\section{Subjects}

32 patients with mild to moderately severe COPD (GOLD stages I and II) were recruited in the outpatient clinics of two participating centres in the Netherlands [1]. Inclusion criteria were symptoms of dyspnoea, chronic cough or sputum production, current or ex-smoking, a smoking history of $\geqslant 20$ packyrs, post-bronchodilator forced expiratory volume in $1 \mathrm{~s}$ (FEV1) $>1.5 \mathrm{~L}$ and $>50 \%$ predicted, and FEV1/forced vital capacity ratio $<0.70$. Patients were excluded in case of exacerbation or respiratory infection $\leqslant 4$ weeks prior to recruitment, and any other pulmonary disease other than COPD, including known asthma. In case of a respiratory infection, a 4-week recovery period was taken into account before re-evaluation for inclusion. Pre-defined subgroups were made with respect to GOLD stages I and II. Before the study, 14 out of 32 patients were on inhaled corticosteroid treatment and stopped this medication at least 4 weeks prior to the study.

The study was approved by the hospital medical ethics committees of the Academic Medical Centre, Amsterdam and Spaarne Hospital, Hoofddorp, the Netherlands, and all patients gave their written informed consent. The study was registered in the Netherlands trial register (www.trialregister. nl), with identifier NTR 1283.

\section{Design}

The study had a cross-sectional design and comprised two study days. At the screening visit, inclusion and exclusion criteria were examined, and lung function tests were performed.
At the second visit, exhaled breath was captured for analysis by GC-MS, eNose and FeNO analyser, sputum was induced by hypertonic saline, atopy was assessed and a venous blood sample was obtained. Before sputum induction and exhaled breath analysis, patients were asked to refrain from eating, drinking and smoking for $2 \mathrm{~h}$, short-acting bronchodilators for $12 \mathrm{~h}$, and long-acting bronchodilators, anti-cholinergics, leukotriene antagonists, and anti-histamines for $24 \mathrm{~h}$.

The sample size was based on the following consideration: if molecular compounds or eNose breathprints are to be used in clinical practice to identify involvement of inflammatory pathways, their association should be considerable. We defined the association to be potentially useful if the correlation coefficient was larger than $0.6 / 0.7$. To find such correlations statistically significant $(\alpha=0.05)$ with $80 \%$ power, 17 and 11 patients were required, respectively.

\section{Measurements}

Lung function and allergy testing

Spirometry (MasterscreenPneumo; Jaeger, Würzburg, Germany) was performed according to the latest European Respiratory Society (ERS) recommendations [20]. Diffusion capacity of the lung for carbon monoxide was measured according to the recommendations using the single-breath method and was corrected for haemoglobin level [21]. FeNO was measured with a portable analyser (flow rate $50 \mathrm{~mL} \cdot \mathrm{s}^{-1}$; NIOX Mino System; Aerocrine, Solna, Sweden) according to American Thoracic Society guidelines [22].

Allergy testing was performed using a skin prick test to 12 common airborne allergens (ALK-Abello, Almere, the Netherlands) or radioallergosorbent test (RAST). Atopy was indicated by positivity ( $>3 \mathrm{~mm}$ wheal) to one or more allergens, or positive RAST.

\section{Sputum induction and processing}

Sputum was induced by inhalation of sodium chloride aerosols three times at intervals of 5 min duration, according to the ERS recommendations [23]. Prior to each sputum induction, $200 \mu \mathrm{g}$ salbutamol was inhaled. All sputum samples were collected in sterile containers and processed within $2 \mathrm{~h}$.

Sputum processing was done by the validated, so-called fullsample technique using dithiothreitol [24]. Differential cell counts were based on 500 non-squamous cells and expressed as percentage of non-squamous cells. Absolute cell numbers were calculated as $(\%$ cell $\times$ total cell count $) /$ sputum weight. Sputum samples containing $>20 \%$ squamous cells were excluded from analysis. All sputum and blood cell counts were performed by experienced and qualified technicians who were blinded to the clinical details.

As biomarkers of local activation of eosinophils and neutrophils, respectively, levels of ECP (detection limit $>60 \mathrm{pg} \cdot \mathrm{mL}^{-1}$ ) and MPO (detection limit $>1.5 \mathrm{ng} \cdot \mathrm{mL}^{-1}$ ) were measured by ELISA in sputum supernatant [25].

\section{Exhaled breath collection}

Exhaled breath collection was carried out as previously described $[16,26]$. Patients breathed normally for 5 min with the nose clipped, through a mouthpiece connected to a threeway non-rebreathing valve, an inspiratory VOC filter (A2; 
North Safety, Middelburg, the Netherlands) and an expiratory silica reservoir for conditioning of the humidity level. After a single deep maximal inspiration, the patient exhaled one vital capacity volume into a 10-L Tedlar bag (SKC Inc.; Eighty Four, PA, USA) connected to the expiratory port and the silica reservoir. In addition, a Tedlar bag was filled with VOCfiltered room air for comparison (background air sample).

Breath analysis by GC-MS was performed as previously described $[16,26]$. The content of the Tedlar bags was transported by a vacuum pump $\left(0.5 \mathrm{~L}\right.$ at a flow rate $\left.200 \mathrm{~mL} \cdot \mathrm{s}^{-1}\right)$ into stainless steel adsorption tubes (Supelco, Zwijndrecht, the Netherlands), filled with Tenax GR (Varian Chrompack, Middelburg, the Netherlands). Tubes were placed inside the thermal desorption unit (TDSA; Gerstel, Mülheim an der Ruhr, Germany) and were thermally desorbed for $10 \mathrm{~min}$ at $200^{\circ} \mathrm{C}$ using helium (temperature gradient of $60^{\circ} \mathrm{C} \cdot \mathrm{min}^{-1}$ ) with a gas flow rate of $15 \mathrm{~mL} \cdot \mathrm{min}^{-1}$ in order to transfer the VOCs into the GC capillary column. Solvent venting mode was used to transfer the entire sample to the packed liner (filled with Tenax TA), held at $0^{\circ} \mathrm{C}$. After collection of the VOCs in the packed liner, it was heated to $300^{\circ} \mathrm{C}$. To minimise band broadening caused by the splitless injection from the packed liner, a cold trap (CTS2; Gerstel, Mülheim an der Ruhr, Germany) was used with the initial temperature set at $-150^{\circ} \mathrm{C}$. After $2 \mathrm{~min}$ the trap was heated to $280^{\circ} \mathrm{C}$ at $20^{\circ} \mathrm{C} \cdot \mathrm{s}^{-1}$. The VOCs were separated by capillary gas chromatography using helium as the carrier gas at $1.2 \mathrm{~mL} \cdot \mathrm{min}^{-1}(6890 \mathrm{~N} \mathrm{GC}$; Agilent, Santa Clara, CA, USA) on a VF1-MS column $(30 \mathrm{~m} \times 0.25 \mathrm{~mm}$, film thickness $1 \mu \mathrm{m}, 100 \%$ dimethylpolysiloxane; Varian Chrompack). The following temperature programme was applied for the gas chromatograph: $40^{\circ} \mathrm{C}$ isothermal for $5 \mathrm{~min}$, then raised at $10^{\circ} \mathrm{C} \cdot \mathrm{min}^{-1}$ until $300^{\circ} \mathrm{C}$, then held isothermal for $5 \mathrm{~min}$. For detection and identification of the separated compounds, a quadrupole mass spectrometer (5975 MSD; Agilent) was used in electron ionisation mode at $70 \mathrm{eV}$, with a scan range of 14-300 Da.

Gaseous calibration standards using 10 ppmv toluene in nitrogen (Air Products, Amsterdam, the Netherlands) were made by use of a home-built dilution system and loaded onto adsorption tubes to check the sensitivity of the system. Reproducibility of exhaled breath samples analysed by GC-MS has been shown to be highly adequate [27].

\section{Breath analysis by eNose}

Within 10 min after breath collection, the Cyranose 320 eNose (Smiths Detection, Pasadena, CA, USA) was connected to the Tedlar bag, followed by 1 min sampling of the exhaled air, in parallel to sampling a Tedlar bag filled with VOC-filtered room air (background air) for comparison $[16,26]$. The changes in electrical resistance of each of the 32 polymer sensors that constitute the raw eNose data [28] were used for further analysis with offline pattern-recognition software. All measurements were performed in duplicate and every first analysis by the eNose during each session was excluded from analysis as recommended by the manufacturer ("first sniff effect") due to deviant sensor deflections. Measurements of breath samples by electronic nose have been shown to be highly reproducible [16].

\section{Statistical analysis}

SPSS (version 17.0; SPSS, Chicago, IL, USA), Graphpad Prism (version 5.01; GraphPad Softward, La Jolla, CA, USA) and MatLab (MathWorks, Natick, MA, USA) were used for data analysis. Results were expressed as mean \pm SD if data were normally distributed and as median (interquartile range) if data were non-normally distributed. Non-normally distributed data were log-transformed for further analysis. If no cells were counted, a value of 0.1 was taken before log-transformation.

The GC-MS chromatograms were aligned using MetAlign software. Details of the software are described elsewhere [29]. Noise values were replaced by zeros and background air chromatograms were subtracted from breath samples. Duplicate breath samples were averaged. The output of the software is a peak table that was exported into MatLab. The correlation coefficient and the corresponding $\mathrm{p}$-value between the peaks and the measured inflammatory parameter were calculated. In view of multiple testing, a p-value of $<0.01$ was considered significant (Šidák correction based on correlation coefficient $>0.6$ ). Compounds representing significantly correlated peaks were identified by comparison of mass spectra to the National Institute of Standards and Technology (Gaithersburg, MD, USA) library and checked manually by an experienced mass spectrometrist.

eNose raw data (change in resistance of sensors) were restructured by principal component analysis from the original 32 sensors to four principal components (PCs) that captured $96.9 \%$ of the variance within the dataset. The relationship between the markers of airway inflammation and the PCs was analysed using Pearson's correlation coefficient. The PCs (PC 1,2 and 3) showing the most significant correlations were selected for further analysis.

For ECP and MPO, receiver operating characteristic (ROC) analysis was performed to assess the detection rate (sensitivity)

\begin{tabular}{lccc} 
TABLE 1 Subject characteristics & & \\
& $\begin{array}{c}\text { All COPD } \\
\text { subjects }\end{array}$ & $\begin{array}{c}\text { GOLD } \\
\text { stage I }\end{array}$ & $\begin{array}{c}\text { GOLD } \\
\text { stage II }\end{array}$ \\
& 28 & 12 & 16 \\
Subjects n & & & \\
Clinical characteristics & $82 / 18$ & $83 / 17$ & $81 / 19$ \\
Sex male/female \% & $43 / 57$ & & \\
GOLD stage I/II \% & $58 \pm 8$ & $59 \pm 7$ & $58 \pm 8$ \\
Age yrs & $43 / 57$ & $50 / 50$ & $38 / 62$ \\
Current/ex-smoker \% & $40 \pm 16$ & $43 \pm 14$ & $39 \pm 17$ \\
Smoking history pack-yrs & 11 & 8 & 12 \\
Atopy \% & 50 & $25^{*}$ & $69^{\star}$ \\
ICS before study & & & \\
Lung function & & & \\
Postbronchodilator FEV 1 L & $2.57 \pm 0.63$ & $2.99 \pm 0.67$ & $2.25 \pm 0.39$ \\
Postbronchodilator FEV 1 & $77 \pm 14$ & $90 \pm 7^{*}$ & $67 \pm 8^{*}$ \\
$\quad \%$ pred & & & \\
FEV $1 /$ FVC & $0.55 \pm 0.08$ & $0.57 \pm 0.07$ & $0.53 \pm 0.09$ \\
DL,CO \% pred & $65 \pm 15$ & $64 \pm 15$ & $66 \pm 15$ \\
\hline
\end{tabular}

Data are presented as mean \pm SD, unless otherwise stated. COPD: chronic obstructive pulmonary disease; GOLD: Global Initiative for Chronic Obstructive Lung Disease; ICS: inhaled corticosteroids; FEV1: forced expiratory volume in $1 \mathrm{~s}$; \% pred: \% predicted; FVC: forced vital capacity; $D L, C O$ : diffusing capacity of the lung for carbon monoxide. *: $p<0.05$ when comparing GOLD stages I and II. 


\begin{tabular}{|c|c|c|c|}
\hline Exhaled NO ppb & $14(9-23)$ & $13(9-29)$ & $19(8-23)$ \\
\hline Sputum neutrophils $10^{4} \cdot \mathrm{mL}^{-1}$ & $110(45-243)$ & $153(76-326)$ & $78(37-229)$ \\
\hline Sputum neutrophils \% & $77.2(70.8-86.0)$ & $76.9(71.3-85.2)$ & $77.2(67.4-86.1)$ \\
\hline Sputum eosinophils \% & $0.8(0.4-3.1)$ & $0.7(0.3-2.9)$ & $1.0(0.3-4.2)$ \\
\hline Sputum ECP $\mathbf{n g} \cdot \mathrm{mL}^{-1}$ & $152(90-452)$ & $130(57-361)$ & $158(100-532)$ \\
\hline Sputum MPO $\mathrm{ng} \cdot \mathrm{mL}^{-1}$ & $4530(1187-7103)$ & $4551(1795-8313)$ & $4078(592-6318)$ \\
\hline Sputum IL-8 pg $\cdot \mathrm{mL}^{-1}$ & 1946 (592-6522) & $1815(579-4754)$ & 2029 (839-8791) \\
\hline Blood neutrophils \% & $55.9 \pm 9.1$ & $57.6 \pm 9.2$ & $54.6 \pm 9.0$ \\
\hline Blood eosinophils \% & $2.7(1.8-4.3)$ & $2.9(1.7-5.4)$ & $2.7(1.8-3.9)$ \\
\hline
\end{tabular}

Data are presented as mean \pm SD or median (interquartile range), unless otherwise stated. COPD: chronic obstructive pulmonary disease; GOLD: Global Initiative for Chronic Obstructive Lung Disease; NO: nitric oxide; ECP: eosinophil cationic protein; MPO: myeloperoxidase; IL: interleukin; CRP: C-reactive protein.

and false-positive rate (1-specificity) of eNose principal components for airway inflammation. As there is no consensus about cut-off points for ECP and MPO in inflammatory subtypes in COPD, quartiles were taken as cut-off points for absence or presence of eosinophilic and neutrophilic inflammation. For each of the quartile cut-off points (25, 50 and 75\%), the Youden index was calculated, and the quartile with the highest Youden index was selected as the best fitting model. The breathprint PC values with the best combination of detection and false-positive rate were considered as the definite eNose PC cut-off points for prediction of ECP and MPO by ROC analysis.

\section{RESULTS}

\section{Subjects}

28 out of 32 patients completed the study. Four patients dropped out for reasons of non-compliance with medication restrictions $(n=1)$, loss to follow up $(n=1)$, FEV1 $<1.2$ L prior to sputum induction $(n=1)$ and inability to perform techniques necessary to measure lung function $(n=1)$. Five hypertonic saline-induced sputum samples were excluded from analysis

\begin{tabular}{lccc} 
TABLE 3 & $\begin{array}{l}\text { Number of exhaled compounds that have a } \\
\text { significant correlation (correlation coefficient } \\
>0.6) \text { with sputum inflammatory markers } \\
(p<0.01)\end{array}$ \\
\hline Compounds correlating with & $\begin{array}{c}\text { All COPD } \\
\text { patients }\end{array}$ & GOLD I & GOLD II \\
\hline Sputum eosinophils & 8 & 1 & 8 \\
Sputum neutrophils & 17 & 2 & 19 \\
Sputum ECP & 0 & 18 & 10 \\
Sputum MPO & 2 & 4 & 3 \\
\hline
\end{tabular}

Data are presented as $\mathrm{n}$. COPD: chronic obstructive pulmonary disease; GOLD: Global Initiative for Chronic Obstructive Lung Disease; ECP: eosinophil cationic protein; MPO: myeloperoxidase. because of the presence of $>80 \%$ non-squamous cells. Baseline characteristics are summarised in table 1. Apart from significant differences in postbronchodilator FEV1 (L and \% pred) $(p=0.001)$, only the use of inhaled corticosteroids (ICS) 4 weeks prior to the study differed between GOLD stages I and II $(p=0.022)$. Cellular and soluble markers of airway inflammation in exhaled air, sputum and blood (table 2) showed no significant differences between GOLD stages I and II.

\section{Relationship between exhaled compounds identified by GC-MS and inflammatory cell counts}

26 different VOCs in the exhaled breath samples of the study population were found to be significantly correlated to markers

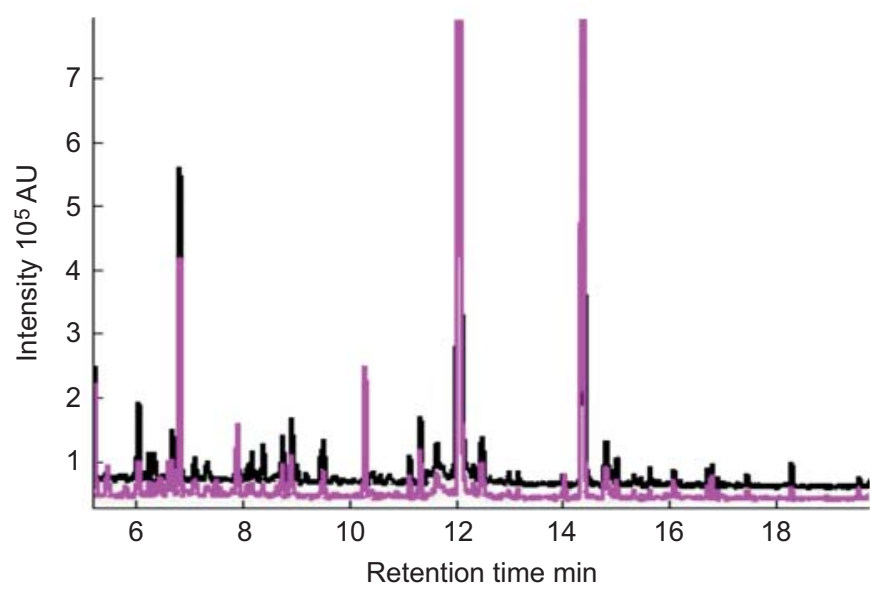

FIGURE 1. Overlay of two gas chromatography-mass spectrometry chromatograms. The magenta-coloured chromatogram corresponds to a Global Initiative for Chronic Obstructive Lung Disease (GOLD) stage I chronic obstructive pulmonary disease (COPD) patient and the black chromatogram to a GOLD stage II COPD patient. The two large peaks are artefacts that were not included in the analyses (Tedlar bag-associated compounds being present in all samples: phenol and $\mathrm{N}, \mathrm{N}$-dimethylacetamide). AU: arbitrary units. 
TABLE 4 Tentative exhaled compound identification for the total chronic obstructive pulmonary disease group

\begin{tabular}{|c|c|c|c|c|c|}
\hline \multirow{2}{*}{$\begin{array}{l}\text { Retention time } \\
\text { min }\end{array}$} & \multirow[t]{2}{*}{ Tentative compound assignment } & \multirow[t]{2}{*}{ Chemical class } & \multicolumn{2}{|c|}{ Correlation with } & \multirow{2}{*}{$\begin{array}{l}\text { Correlation } \\
\text { coefficient }\end{array}$} \\
\hline & & & Sputum eosinophils \% & Sputum neutrophils \% & \\
\hline 4.82 & Unknown & & & $x$ & 0.56 \\
\hline 5.01 & Pentane & Alkanes & & $x$ & 0.55 \\
\hline 5.38 & Unknown & & & $x$ & -0.55 \\
\hline 7.37 & Unknown & & & $x$ & -0.57 \\
\hline 7.70 & Benzene & Aromatic hydrocarbons & & $x$ & -0.59 \\
\hline 8.34 & 3-Methylhexane & Methyl-branched alkanes & & $x$ & -0.59 \\
\hline 8.80 & Trichloroethylene & Chlorinated hydrocarbons & & $x$ & -0.56 \\
\hline 10.14 & Toluene & Aromatic hydrocarbons & & $x$ & -0.64 \\
\hline 10.33 & 2-Methylpentane & Methyl-branched alkanes & & $x$ & -0.55 \\
\hline 13.76 & Dimethyloctane & Methyl-branched alkanes & & $x$ & -0.57 \\
\hline 15.01 & Branched alkane ${ }^{\#}$ & Alkanes & & $x$ & -0.56 \\
\hline 15.36 & Alkylated benzene ${ }^{\#}$ & Alkyl benzenes & $x$ & $x$ & 0.56 \\
\hline 15.84 & Branched alkane ${ }^{\#}$ & Alkanes & & $x$ & -0.58 \\
\hline 16.22 & Unknown & & $x$ & & 0.58 \\
\hline 16.31 & 5-Nonanol & Alcohols & $x$ & & 0.56 \\
\hline 16.50 & Dimethyl-3-octanol & Alcohols & $x$ & & 0.61 \\
\hline 17.38 & Unknown & & $x$ & & -0.59 \\
\hline 18.54 & Unknown & & & $x$ & -0.60 \\
\hline
\end{tabular}

$X$ indicates a correlation. ${ }^{\#}$ : The exact chain length of the alkyl moieties could not be determined from the mass spectra.

of airway inflammation (table 3). Figure 1 shows typical GC-MS chromatograms of GOLD stage I and II patients. Only one compound (alkylated benzene; table 4) was indicative for both cell types and more compounds correlated strongly with sputum neutrophils than with eosinophils. The exact molecular identity of the alkylated benzene could not be determined due to the high similarity of the mass spectra of homologues in this class of compounds. Between the two disease stages, more compounds were found to correlate with cell counts for GOLD stage II patients (table 3$)$. Compounds that correlated $(p<0.01)$ with sputum cell counts were mostly larger hydrocarbons (alkanes, methyl-branched alkanes, aromatic compounds).

\section{Relationship between exhaled compounds identified by GC-MS and inflammatory cell activation}

Exhaled compounds were also found to be associated with markers of inflammatory cell activation: ECP for eosinophils and MPO for neutrophils (table 3). Notably, correlated compounds were largely different between the GOLD stages. For GOLD stage I, 18 compounds were identified that significantly correlated with ECP and four with MPO. For GOLD stage II and $\mathrm{ECP}$, nine different compounds and one identical compound were found compared with GOLD stage I. For GOLD stage II and $\mathrm{MPO}$, one different compound and two identical compounds were found compared with GOLD stage I (table 3).

\section{Relationship between eNose exhaled breathprints and inflammatory cell counts and activation}

The associations of eNose breathprints with ECP and MPO were consistent with those observed with GC-MS, showing more prominent correlations in mild compared with moderate disease (fig. 2). For GOLD stage I, there was a strong correlation between exhaled breathprint PC2 and ECP ( $r=0.84, p=0.002$; fig. $2 b)$ and MPO ( $r=0.72, p=0.008$; fig. $2 e)$.

For GOLD stage II, none of the correlations found in GOLD stage I could be observed. There were no significant correlations between breathprints and levels of ECP (fig. 2c) and MPO (fig. 2f).

No significant correlations were found between breathprints and sputum differential cell counts, and between FeNO and cell counts or markers of cell activation.

\section{Performance estimation of exhaled breathprints for inflammatory activity}

The detection (sensitivity) and false-positive rates (1-specificity) of exhaled breathprints for sputum ECP and MPO are listed in table 5. For sputum ECP, the 50th percentile (cut-off at $152 \mathrm{ng} \cdot \mathrm{mL}^{-1}$ ) showed an area under the curve (AUC) of the ROC curve of 0.86 for the total COPD group (fig. 3a). Split analysis for GOLD stages I and II showed a good performance of breathprint PC2 for sputum ECP in mild COPD (AUC 1.00; 

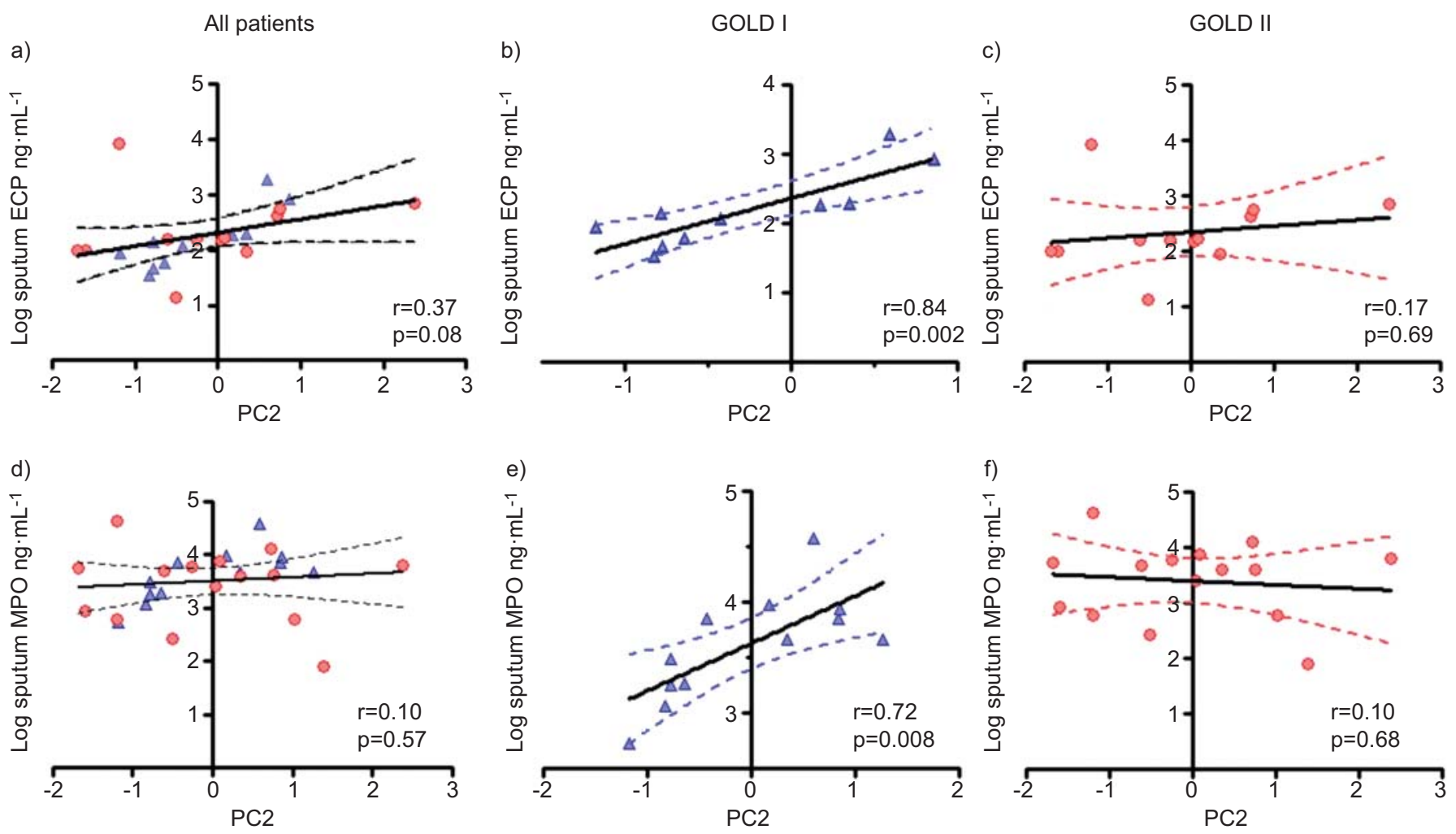

FIGURE 2. Correlations, linear regression lines and $95 \%$ confidence bands of eNose breathprint principal component (PC)2 in a, d) all patients; b, e) Global Initiative for Chronic Obstructive Lung Disease (GOLD) stage I patients; and c, f) GOLD stage II patients, to a-c) eosinophil cationic protein (ECP) and d-f) myeloperoxidase (MPO).

cut-off 75 th percentile at $\left.361 \mathrm{ng} \cdot \mathrm{mL}^{-1}\right)$ (fig. 3b) but a weaker performance in moderate COPD (AUC 0.75; cut-off 50th percentile at $158 \mathrm{ng} \cdot \mathrm{mL}^{-1}$ ) (fig. 3c).

For MPO, a similar pattern was seen (table 5). In GOLD stage I, the ROC analysis reached an AUC of 0.96 (cut-off 25th percentile at $1,795 \mathrm{ng} \cdot \mathrm{mL}^{-1}$ ) (fig. 3e), as opposed to 0.66 for the total group

\begin{tabular}{|c|c|c|c|c|}
\hline \multirow[t]{2}{*}{ TABLE 5} & \multicolumn{4}{|c|}{$\begin{array}{l}\text { Receiver operating characteristic analysis of } \\
\text { breathprints predictive for airway inflammation } \\
\text { activity }\end{array}$} \\
\hline & AUC & $\begin{array}{c}\text { Optimal cut-off } \\
\mathrm{ng} \cdot \mathrm{mL}^{-1}\end{array}$ & $\begin{array}{l}\text { Detection } \\
\text { rate \% }\end{array}$ & $\begin{array}{c}\text { False-positive } \\
\text { rate \% }\end{array}$ \\
\hline \multicolumn{5}{|l|}{ ECP } \\
\hline All subjects & $0.860^{*}$ & 152 & 73 & 9 \\
\hline GOLD I & $1.000^{*}$ & 361 & 100 & 12 \\
\hline GOLD ॥ & 0.750 & 158 & 67 & 17 \\
\hline \multicolumn{5}{|l|}{ MPO } \\
\hline All subjects & 0.659 & 4530 & 50 & 23 \\
\hline GOLD I & $0.963^{*}$ & 1795 & 89 & 0 \\
\hline GOLD ॥ & 0.659 & 6320 & 75 & 36 \\
\hline
\end{tabular}

AUC: area under the curve; ECP: eosinophil cationic protein; GOLD: Global Initiative for Chronic Obstructive Lung Disease; MPO: myeloperoxidase. *: $p<0.05$. (cut-off 50 th percentile at $4,530 \mathrm{ng} \cdot \mathrm{mL}^{-1}$ ) (fig. $3 \mathrm{~d}$ ) and 0.66 for GOLD stage II (cut-off 75 th percentile at $6,320 \mathrm{ng} \cdot \mathrm{mL}^{-1}$ ) (fig. 3f).

\section{DISCUSSION}

This study shows that exhaled markers are significantly associated with differential cell counts and soluble sputum markers of activated neutrophils and eosinophils in mild and moderately severe COPD. These results indicate that molecular patterns in exhaled breath are related to inflammatory cell type and activation status, suggesting that breath analysis may qualify as a noninvasive marker of airway inflammation in relatively early stages of the disease after confirmation of generalisability in independent studies.

To our knowledge, this is the first study assessing the relationship and estimating the performance of molecular profiles of volatile biomarkers in exhaled air and markers of airway inflammation in sputum of patients with COPD. The present results extend findings in earlier studies, in which COPD could be distinguished from asthma using exhaled breath analysis by eNose [16] and from healthy smoking and nonsmoking controls by GC-MS [30, 31]. In those studies, however, the relationships between exhaled VOC patterns and the accompanying inflammatory profiles were not examined.

In the present study, we carefully selected mild and moderate COPD patients based on objective criteria including fixed airway obstruction and smoking history [1]. Because ICS could have confounded the effects of inflammatory profiles, ICS treatment was withheld for 4 weeks prior to measurements. 

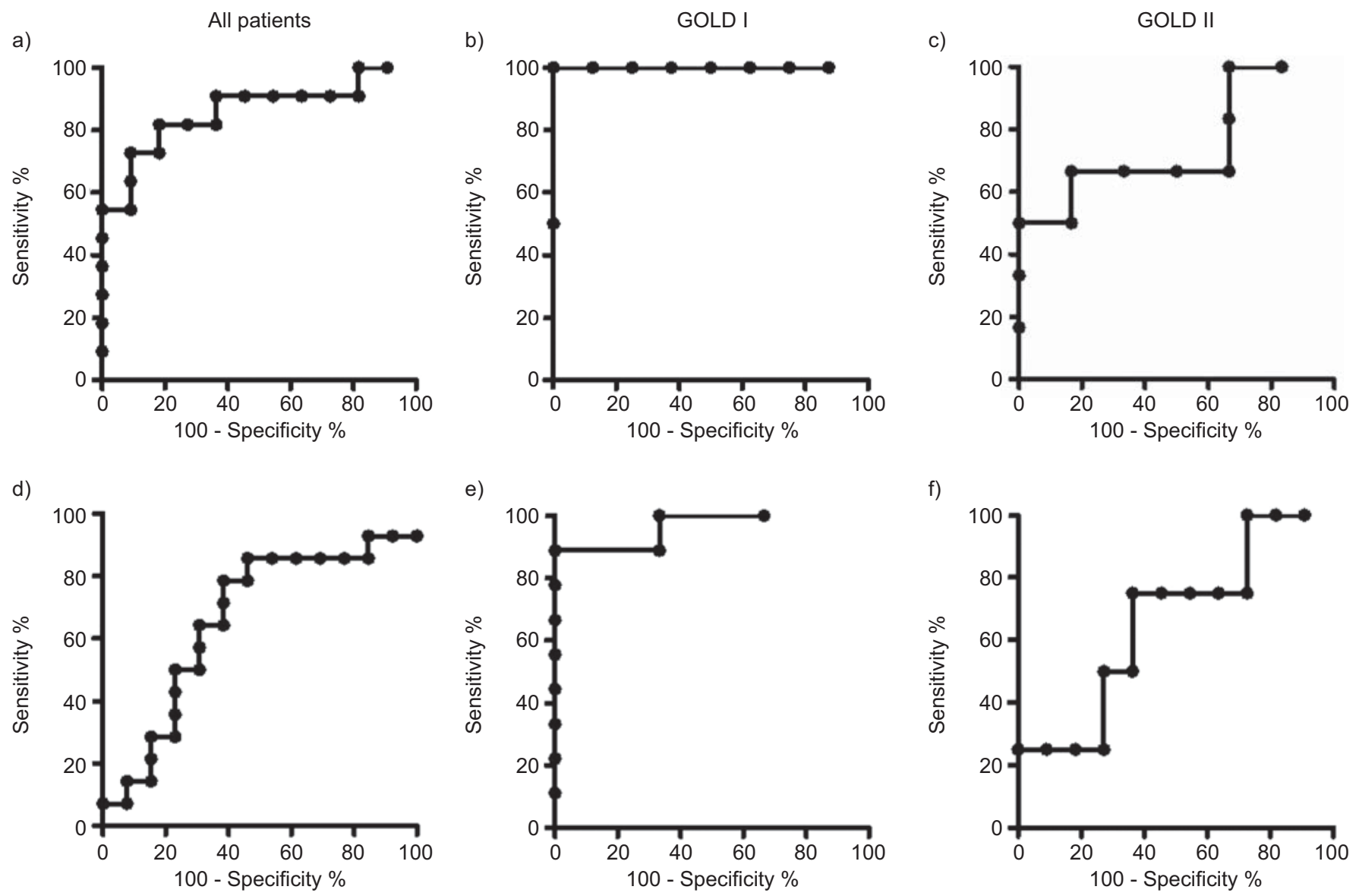

FIGURE 3. Receiver operating characteristic curves with line of identity of breathprint principal component 2 predictive for a-c) sputum eosinophil cationic protein and d-f) myeloperoxidase for a, d) all subjects, b, e) Global Initiative for Chronic Obstructive Lung Disease (GOLD) stage I patients and c, f) GOLD stage II patients.

However, an extended influence of ICS treatment on inflammatory profile cannot be completely excluded. This holds true, especially, for the group of GOLD stage II COPD patients with a higher proportion of previous ICS use, which may have masked findings in this group. Furthermore, the breathprints are critically dependent on the methods of collecting and sampling [16]. We used a validated breathing and sampling procedure with inspiratory VOC filtering to minimise any external influence on the breathprint $[16,26]$ and corrected for ambient air and any influences from the breathing setup by background subtraction. Finally, smoking status could have influenced the results as about half of the patients in this study were current smokers. Several components that were found to be associated with inflammatory markers have previously been described as smoking-related, but have also been described as (ex-smoking) COPD-related [32]. The latter is supported by observations from our previous study, in which we found no difference in eNose breathprints between smoking and exsmoking COPD patients [16].

How can we explain these findings? Earlier studies of exhaled air in inflammatory lung diseases showed a distinct signal when compared with controls [16, 26, 31, 33]. Our present results show that the signal in COPD is most probably based on the metabolites that mediate or that are the result of the accompanying neutrophilic and eosinophilic inflammation
$[2,5,34]$. Exhaled compounds and eNose breathprints were also associated with activation markers of eosinophils and neutrophils, namely MPO and ECP, the predominant VOCs being alkanes, methylated alkanes, aromatic compounds like benzene and toluene, and alcohols. These hydrocarbons can be seen as markers of oxidative stress resulting from lipid peroxidation by the formation of reactive oxidising and chlorinating species [32, 35-37]. Indeed, one of the major biological activities of ECP [38] and MPO [39, 40] is their cytotoxic effect by the formation of reactive oxygen species. Alkanes are cleared either by diffusion through the lungs, or by further oxidation to alcohols by cytochrome P450 enzymes [41], which are also known to play a role in the pathogenesis of COPD [42]. Therefore, the complex nature of the inflammation in COPD probably makes metabolomic assessment of biomarkers a suitable approach, as a single marker that is representative of the airway inflammation in COPD has not been identified $[13,43,44]$.

Our findings suggest that exhaled breath profiling using the quantitative GC-MS method can identify both the type and the activation of inflammation (eosinophilic versus neutrophilic), whereas multi-compound breath profiling using nano-sensor pattern recognition by eNose appeared to be more suitable for detecting activation of inflammatory cells, especially in GOLD stage I COPD. It is tempting to speculate that the inflammatory 
drive and activity in early stages of COPD are reflected differentially or more prominently in exhaled breath than in more advanced stages of COPD. This is in concordance with the findings by PIERROU et al. [17], who observed a peak in oxidative stress gene expression in mild COPD as compared with more severe stages of the disease [17]. Therefore, the findings of the present study suggest that inflammatory activity as revealed by exhaled breath analysis depends on disease severity, being more prominent in mild COPD. This favours the hypothesis that inflammatory activity diminishes or alters with disease progression in COPD [18, 19], which requires prospective follow-up studies.

The clinical implications of our findings are in the area of potential application of exhaled breath profiling in the phenotyping and monitoring of COPD. It is increasingly recognised that COPD is not a single disease entity, and that phenotypic fingerprints derived from both clinical and inflammatory markers are needed to predict disease progression and therapeutic responses [43]. Exhaled markers are certainly appealing in this respect. Our study represents a first step towards such an application by demonstrating strong associations between differential cell counts in sputum and exhaled volatiles, and good performance of exhaled eNose breathprints for estimation of inflammatory activity in the airways. Other independent studies should be undertaken to confirm our findings by external validation [45]. In addition, it needs to be examined whether breath profiling has sufficient diagnostic accuracy for assessing early stage COPD among smokers. And finally, it should be established whether breath volatiles can adequately predict responsiveness to inhaled steroid treatment, as observed by using sputum eosinophils in mild and more severe stages of the disease [10, 11, 43].

In conclusion, the present data show that exhaled molecular profiling by GC-MS and by eNose is closely associated with cell counts and markers of inflammatory cell activation in induced sputum of patients with COPD. This suggests that metabolomic breath analysis can be a candidate method for the noninvasive identification of the cell type and their activation in COPD.

\section{SUPPORT STATEMENT}

This study was supported by grant 3.2.06.17 of the Netherlands Asthma Foundation (Amersfoort, The Netherlands).

\section{CLINICAL TRIAL}

This study is listed on www.trialregister.nl with identifier NTR 1283.

\section{STATEMENT OF INTEREST}

Statements of interest for H.H. Knobel, T.J. Vink and N.P. Willard can be found at erj.ersjournals.com/site/misc/statements.xhtml

\section{ACKNOWLEDGEMENTS}

The authors thank B. Smids, (Dept of Experimental Immunology, Academic Medical Centre, Amsterdam, The Netherlands) and the participating patients for their contribution to this study.

\section{REFERENCES}

1 Rabe KF, Hurd S, Anzueto A, et al. Global strategy for the diagnosis, management, and prevention of chronic obstructive pulmonary disease: GOLD executive summary. Am J Respir Crit Care Med 2007; 176: 532-555.

2 Lapperre TS, Snoeck-Stroband JB, Gosman MM, et al. Dissociation of lung function and airway inflammation in chronic obstructive pulmonary disease. Am J Respir Crit Care Med 2004; 170: 499-504.

3 Gibson PG, Simpson JL. The overlap syndrome of asthma and COPD: what are its features and how important is it? Thorax 2009; 64: 728-735.

4 Beasley R, Weatherall $\mathrm{M}$, Travers $\mathrm{J}$, et al. Time to define the disorders of the syndrome of COPD. Lancet 2009; 374: 670-672.

5 Turato G, Zuin R, Miniati M, et al. Airway inflammation in severe chronic obstructive pulmonary disease: relationship with lung function and radiologic emphysema. Am J Respir Crit Care Med 2002; 166: 105-110.

6 Barnes PJ, Chowdhury B, Kharitonov SA, et al. Pulmonary biomarkers in chronic obstructive pulmonary disease. Am J Respir Crit Care Med 2006; 174: 6-14.

7 Louis RE, Cataldo D, Buckley MG, et al. Evidence of mast-cell activation in a subset of patients with eosinophilic chronic obstructive pulmonary disease. Eur Respir J 2002; 20: 325-331.

8 Snoeck-Stroband JB, Lapperre TS, Gosman MM, et al. Chronic bronchitis sub-phenotype within COPD: inflammation in sputum and biopsies. Eur Respir J 2008; 31: 70-77.

9 Brightling CE, Monteiro W, Ward R, et al. Sputum eosinophilia and short-term response to prednisolone in chronic obstructive pulmonary disease: a randomised controlled trial. Lancet 2000; 356: 1480-1485.

10 Leigh R, Pizzichini MM, Morris MM, et al. Stable COPD: predicting benefit from high-dose inhaled corticosteroid treatment. Eur Respir J 2006; 27: 964-971.

11 Siva R, Green RH, Brightling $\mathrm{CE}$, et al. Eosinophilic airway inflammation and exacerbations of COPD: a randomised controlled trial. Eur Respir J 2007; 29: 906-913.

12 Nicholas B, Djukanovic R. Induced sputum: a window to lung pathology. Biochem Soc Trans 2009; 37: 868-872.

13 Richens JL, Urbanowicz RA, Lunt EA, et al. Systems biology coupled with label-free high-throughput detection as a novel approach for diagnosis of chronic obstructive pulmonary disease. Respir Res 2009; 10: 29.

14 Silverman EK, Spira A, Pare PD. Genetics and genomics of chronic obstructive pulmonary disease. Proc Am Thorac Soc 2009; 6: 539-542.

15 Röck F, Barsan N, Weimar U. Electronic nose: current status and future trends. Chem Rev 2008; 108: 705-725.

16 Fens N, Zwinderman AH, van der Schee MP, et al. Exhaled breath profiling enables discrimination of chronic obstructive pulmonary disease and asthma. Am J Respir Crit Care Med 2009; 180: 1076-1082.

17 Pierrou S, Broberg P, O'Donnell RA, et al. Expression of genes involved in oxidative stress responses in airway epithelial cells of smokers with chronic obstructive pulmonary disease. Am J Respir Crit Care Med 2007; 175: 577-586.

18 Harju T, Mazur W, Merikallio H, et al. Glutathione-S-transferases in lung and sputum specimens, effects of smoking and COPD severity. Respir Res 2008; 9: 80.

19 Francis SM, Larsen JE, Pavey SJ, et al. Expression profiling identifies genes involved in emphysema severity. Respir Res 2009; 10: 81 .

20 Miller MR, Hankinson J, Brusasco V, et al. Standardisation of spirometry. Eur Respir J 2005; 26: 319-338.

21 Macintyre N, Crapo RO, Viegi G, et al. Standardisation of the single-breath determination of carbon monoxide uptake in the lung. Eur Respir J 2005; 26: 720-735.

22 American Thoracic Society, European Respiratory Society. ATS/ERS recommendations for standardized procedures for the online and offline measurement of exhaled lower respiratory nitric oxide and nasal nitric oxide, 2005. Am J Respir Crit Care Med 2005; 171: 912-930.

23 Paggiaro PL, Chanez P, Holz O, et al. Sputum induction. Eur Respir J 2002; 20: Suppl. 37, 3s-8s. 
24 Efthimiadis A, Spanevello A, Hamid Q, et al. Methods of sputum processing for cell counts, immunocytochemistry and in situ hybridisation. Eur Respir J 2002; 20: Suppl. 37, 19s-23s.

25 Boorsma M, Lutter R, van de Pol MA, et al. Repeatability of inflammatory parameters in induced sputum of COPD patients. COPD 2007; 4: 321-329.

26 Dragonieri S, Schot R, Mertens BJ, et al. An electronic nose in the discrimination of patients with asthma and controls. J Allergy Clin Immunol 2007; 120: 856-862.

27 Van Berkel JJ, Dallinga JW, Moller GM, et al. Development of accurate classification method based on the analysis of volatile organic compounds from human exhaled air. J Chromatogr B Analyt Technol Biomed Life Sci 2008; 861: 101-107.

28 Lewis NS. Comparisons between mammalian and artificial olfaction based on arrays of carbon black-polymer composite vapor detectors. Acc Chem Res 2004; 37: 663-672.

29 Lommen A. MetAlign: interface-driven, versatile metabolomics tool for hyphenated full-scan mass spectrometry data preprocessing. Anal Chem 2009; 81: 3079-3086.

30 Basanta M, Jarvis RM, Xu Y, et al. Non-invasive metabolomic analysis of breath using differential mobility spectrometry in patients with chronic obstructive pulmonary disease and healthy smokers. Analyst 2010; 135: 315-320.

31 Van Berkel JJ, Dallinga JW, Moller GM, et al. A profile of volatile organic compounds in breath discriminates COPD patients from controls. Respir Med 2010; 104: 557-563.

32 Poli D, Carbognani P, Corradi M, et al. Exhaled volatile organic compounds in patients with non-small cell lung cancer: cross sectional and nested short-term follow-up study. Respir Res 2005; 6: 71.

33 Montuschi P, Santonico M, Mondino C, et al. Diagnostic performance of an electronic nose, fractional exhaled nitric oxide, and lung function testing in asthma. Chest 2010; 137: 790-796.

34 Bhattacharya S, Srisuma S, Demeo DL, et al. Molecular biomarkers for quantitative and discrete COPD phenotypes. Am J Respir Cell Mol Biol 2009; 40: 359-367.
35 Phillips M, Cataneo RN, Greenberg J, et al. Effect of age on the breath methylated alkane contour, a display of apparent new markers of oxidative stress. J Lab Clin Med 2000; 136: 243-249.

36 Risby TH, Sehnert SS. Clinical application of breath biomarkers of oxidative stress status. Free Radic Biol Med 1999; 27: 1182-1192.

37 Wang C, Sahay P. Breath analysis using laser spectroscopic techniques: breath biomarkers, spectral fingerprints, and detection limits. Sensors 2009; 9: 8230-8262.

38 Venge P, Bystrom J. Eosinophil cationic protein (ECP). Int J Biochem Cell Biol 1998; 30: 433-437.

39 van der Veen BS, de Winther MP, Heeringa P. Myeloperoxidase: molecular mechanisms of action and their relevance to human health and disease. Antioxid Redox Signal 2009; 11: 2899-2937.

40 Thukkani AK, Hsu FF, Crowley JR, et al. Reactive chlorinating species produced during neutrophil activation target tissue plasmalogens: production of the chemoattractant, 2-chlorohexadecanal. J Biol Chem 2002; 277: 3842-3849.

41 Scheller U, Zimmer T, Kargel E, et al. Characterization of the $\mathrm{n}$ alkane and fatty acid hydroxylating cytochrome P450 forms 52A3 and 52A4. Arch Biochem Biophys 1996; 328: 245-254.

42 Ben-Zaken CS, Pare PD, Man SF, et al. The growing burden of chronic obstructive pulmonary disease and lung cancer in females: examining sex differences in cigarette smoke metabolism. Am J Respir Crit Care Med 2007; 176: 113-120.

43 Anderson D, MacNee W. Targeted treatment in COPD: a multisystem approach for a multi-system disease. Int J Chron Obstruct Pulmon Dis 2009; 4: 321-335.

44 Roy K, Smith J, Kolsum U, et al. COPD phenotype description using principal components analysis. Respir Res 2009; 10: 41.

45 Fens N, Roldaan AC, van der Schee MP, et al. External validation of exhaled breath profiling using an electronic nose in the discrimination of asthma with fixed airways obstruction and chronic obstructive pulmonary disease. Clin Exp Allergy 2011; [Epub ahead of print DOI: 10.1111/j.1365-2222.2011.03800.x]. 